\title{
High Temperature Characterization of a CMOS Based Infra-red Source using Thermal-incandescence Microscopy
}

\author{
Prakash Pandey ${ }^{\mathrm{a} *}$ Chris Oxley ${ }^{\mathrm{a}}$, Richard H. Hopper ${ }^{\mathrm{b}}$, Florin Udrea ${ }^{\mathrm{b}, \mathrm{c}}$, Syed Zeeshan Ali ${ }^{\mathrm{c}}$ \\ ${ }^{a}$ Faculty of Computing, Engineering and Media, De Montfort University, The Gateway, Leicester, LE1 \\ 9BH, United Kingdom \\ ${ }^{b}$ Department of Engineering, University of Cambridge, Cambridge, CB3 OFA, United Kingdom \\ ${ }^{c}$ Flusso Ltd., Deanland House, Cowley Road, Cambridge CB4 ODL, United Kingdom
}

\begin{abstract}
This paper presents the high temperature thermal characterization of a Micro-Electro-Mechanical Systems (MEMS) infra-red (IR) thermal source, using non-contact optical approaches, based on IR and thermo-incandescence microscopy. The IR thermal source was fabricated using a CMOS based processing technology and consists of a miniature micro-heater, fabricated using tungsten metallization. The performance and reliability of the IR source is highly dependent on its operating temperature. For short-wave $(1.4 \mu \mathrm{m}-2.5 \mu \mathrm{m})$ infra-red emission, the operating temperature is in excess of $800^{\circ} \mathrm{C}$. Work will be presented in this paper in which spot temperature measurements $\left(>700^{\circ} \mathrm{C}\right.$ ) were made on the IR source using thermal-incandescence microscopy. Thermal-optical calibration was achieved by utilizing the known melting point (MP) of different metal microparticles. Optical measurements were compared to those obtained using an electrical approach. The thermal measurements suggest good temperature uniformity across the micro-heater of the IR source.
\end{abstract}

Keywords: CMOS technology, MEMS gas sensor, Infra-red radiation, IR thermal microscopy, Optical incandescence radiation, Thermal-incandescence microscopy

\section{Introduction}

This paper reports on the use of optical incandescence thermography for the high temperature characterization (to approximately $1200^{\circ} \mathrm{C}$ ) of a MEMS based IR thermal source utilizing CMOS technology. There are several thermal characterization techniques that can be used to thermally profile micro-scale semiconductor devices [1]. A review of different micro and nano-scale thermal characterization techniques is presented in [2]. Optical methods have been widely used to characterize the thermal behavior of micro-scale electronic devices and have the major benefit of being non-contact and non-invasive. In addition, when compared with electrical methods, a critical advantage with optical method is that, it can be used to image different regions and optical imaging can enable the identification of hot areas within a structure [3].

\footnotetext{
${ }^{*}$ Corresponding author.

Email addresses: prakash.pandey@dmu.ac.uk (Prakash Pandey)
} 
In recent years, miniature mid and short-wave IR emitters are of interest, for use in NonDispersive Infra-red (NDIR) gas sensing and spectroscopy applications [4]. At present many of these applications use a glass micro-bulb as a broadband IR source. The micro-bulb manufacturing costs are low but it suffers from a number of disadvantages, which include high DC power consumption (typically several $100 \mathrm{~mW}$ ) [5], large spatial volume compared to most silicon chip devices, and the IR transmission efficiency is reduced due to optical absorption by the glass envelope in the mid to long IR wavelength range. There are many reports in the literature highlighting different fabrication techniques to realize miniature silicon based IR sources [6], [7], but mostly using non-CMOS MicroElectro-Mechanical Systems (MEMS) processing technologies.

The CMOS based IR source, studied in this work, consists of a micro-heater, fabricated using tungsten metallization, which can be heated to high operating temperatures [8], [9]. The device typically operates at temperatures around $500{ }^{\circ} \mathrm{C}$ [9] to thermally generate optical emission for midIR spectroscopy applications, including optical gas sensing [5]. The chip-scale source has the advantage of having a smaller physical envelope, compared to the micro-bulb based IR source, and can be assembled in a surface mount package.

A future requirement is to operate the CMOS based IR source at higher operating temperatures (> $800{ }^{\circ} \mathrm{C}$ ) for spectral sensing applications in the short-wave region of the IR spectrum $(1.4 \mu \mathrm{m}-2.5 \mu \mathrm{m})$ where many molecules have absorption lines [10], [11]. At elevated operating temperature, the spectral distribution of thermally emitted optical radiation shifts towards shorter wavelengths (as described by Wien's law). If the temperature of an object is sufficiently high, optical radiation can be visibly detected. This effect is noticeable when hot objects start to visibly glow at temperatures approximately $798 \mathrm{~K}$ (known as the Draper point) [12]. At lower temperatures, optical emission due to thermal-incandescence is too weak to be easily detected but thermally emitted radiation in the mid-IR waveband can be detected, for example, using IR microscopy [13].

It is important to maximize thermal uniformity across the micro-heater to ensure consistent IR emission and to minimize the localized hotspots, which could induce thermal stress leading to premature failure. IR thermal microscopy has been used to thermally characterize the temperature distribution on the IR source [13], which showed excellent thermal uniformity to temperatures approaching $700{ }^{\circ} \mathrm{C}$. To enable thermal characterization of the IR source, at elevated temperature (> $700{ }^{\circ} \mathrm{C}$ ), a passive optical approach will be presented in which, uniform thermally emitted incandescent radiation is used.

\section{IR source design and fabrication}

Tungsten has been used as an interconnect metal for high temperature CMOS circuitry because of its very high melting point $\left(>3400{ }^{\circ} \mathrm{C}\right)$ and resistant to electro-migration induced failure, when compared to aluminum or polysilicon [14]. Doped polysilicon has also been widely used for the fabrication of IR thermal emitters due to it being fully CMOS compatible and has good adhesion to other materials. However, polysilicon displays poor long term stability at temperatures above $300^{\circ} \mathrm{C}$ [15], [16]. The use of tungsten enables the design and fabrication of an IR thermal source with longterm stability, having all the advantages of CMOS technology. These advantages include excellent device reproducibility with very low manufacturing cost in high volume and the possibility of integration with a wide range of electronic circuitry. The IR source (die size $1.76 \mathrm{~mm} \times 1.76 \mathrm{~mm}$ ) was fabricated using a $1.0 \mu \mathrm{m}$ CMOS process at a commercial foundry [17]. The CMOS based IR source chip has a miniature tungsten heater, consisting of a circular multi-ring structure $(800 \mu \mathrm{m}$ diameter), embedded within a $5 \mu \mathrm{m}$ thick, $1200 \mu \mathrm{m}$ diameter circular silicon dioxide $\left(\mathrm{SiO}_{2}\right)$, 
dielectric membrane, passivated with silicon nitride $\left(\mathrm{Si}_{3} \mathrm{~N}_{4}\right)$. Silicon oxide layers are used as interlayer dielectrics. The membrane was formed as a post-CMOS process by the same external foundry, using Deep Reactive Ion Etching (DRIE) of the silicon substrate, with the first buried silicon dioxide layer acting as an effective etch stop. The membrane thermally isolates the micro-heater from the substrate, ensuring efficient heating, fast thermal transient response and low power consumption. To enhance IR emission, the thermal source utilizes a plasmonic crystal structure. The plasmonic structure is formed by a geometric arrangement of metallic dots in a metal layer and has previously been reported [17]. In operation, electrical power is applied to the micro-heater element which increases its temperature to over $500{ }^{\circ} \mathrm{C}$. The thermal source emits IR radiation over a broad spectrum of the mid-IR waveband $(2.5 \mu \mathrm{m}-15 \mu \mathrm{m})$ [5]. An optical micrograph of the fabricated chip is shown in Fig. 1a, whereas Fig. 1b shows a schematic cross-section of the device and its layered structures.

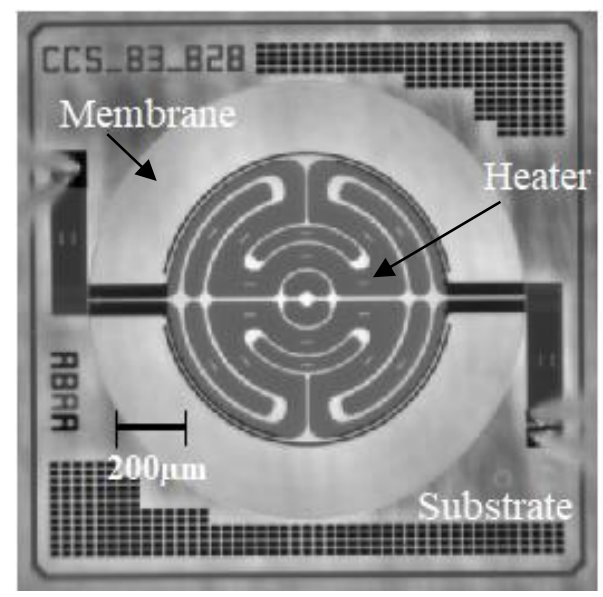

(a)

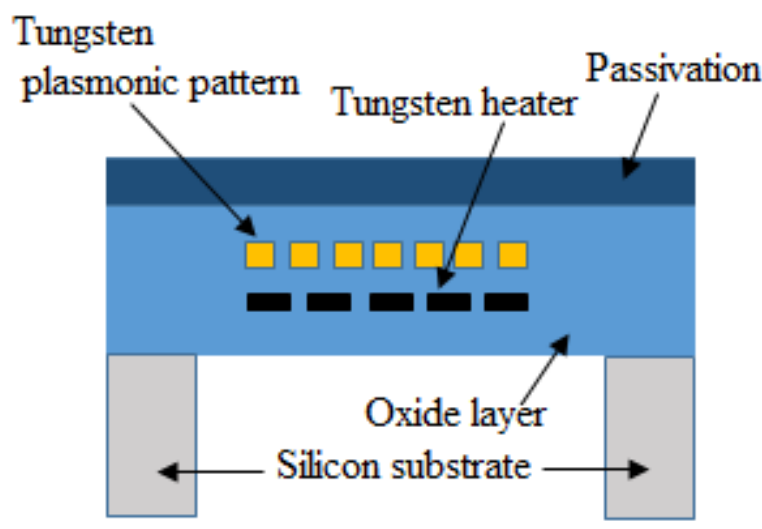

(b)

Fig. 1. (a) Optical micrograph of the fabricated IR source chip; (b) schematic cross- section of the IR source (not to scale).

\section{Thermo-optical measurement theory}

The theory behind the thermo-optical measurement approach described in the work is outlined. The spectral radiance emitted by a blackbody is given by Planck's radiation law [18], which can be expressed as; 


$$
B_{\lambda}(\lambda, T)=\frac{2 h c^{2}}{\lambda^{5}}\left[\exp \left(\frac{h c}{\lambda k_{B} T}\right)-1\right]^{-1} W \cdot m^{-2} \cdot s r^{-1} \cdot \mu m^{-1}
$$

Where, $c$ is speed of light in a vacuum, $h$ is Planck's constant, $k_{B}$ is Boltzmann's constant, $\lambda$ is the wavelength, and $T$ is the absolute temperature of the radiating surface.

Equation 1, can be simplified if;

therefore,

$$
K=2 h c^{2} \text { and } K^{\prime}=\frac{h c}{k_{B}}
$$

$$
B_{\lambda}(\lambda, T)=\frac{K}{\lambda^{5}}\left[\exp \left(\frac{K^{\prime}}{\lambda T}\right)-1\right]^{-1} W \cdot m^{-2} \cdot s r^{-1} \cdot \mu m^{-1}
$$

The spectral radiance of a gray body object will be dependent on its surface emissivity $(\varepsilon)$. Therefore, Equation (2), becomes;

$$
B_{\lambda}^{\prime}(\lambda, T)=\varepsilon(\lambda) \frac{K}{\lambda^{5}}\left[\exp \left(\frac{K^{\prime}}{\lambda T}\right)-1\right]^{-1} W \cdot m^{-2} \cdot s r^{-1} \cdot \mu m^{-1}
$$

To measure radiation emitted by thermal incandescence, the longer wave IR contribution needs to be minimized by including an IR rejection filter. Assuming the spectral response of the IR filter is $F_{I R}(\lambda)$ and the spectral response of the microscope's objective is, $F_{\text {optical }}(\lambda)$, Equation 4 can be used to estimate the emitted radiance as a function of temperature. To simplify the calculation, the following assumptions were made, at temperatures above the Draper point, the IR contribution to the radiation intensity (in $0.4 \mu \mathrm{m}-0.7 \mu \mathrm{m}$ waveband) is significantly smaller than the intensity of the optical (incandescence) radiation [18], and the surface emissivity is invariant with temperature [19].

$$
L(T)=\int_{\lambda_{1}}^{\lambda_{2}} B_{\lambda}^{\prime}(\lambda, T) F_{I R}(\lambda) F_{\text {optical }}(\lambda) d \lambda
$$

\section{Measurement approach}

\subsection{Experimental setup}

To enable thermal-incandescence measurements in the visible spectrum, A Quantum Focus Instrument (QFI) IR microscope (Infrascope II) was modified to include an optical camera (Stingray-F146C from Allied Vision Technologies), fitted with an IR rejection filter (Fig. 2). A mirror system (part of the QFI assembly) was used to switch between the IR detector and the optical camera. The IR detector is a $\mathrm{LN}_{2}$ cooled $512 \times 512$ pixel indium antimony (InSb) focal plane array with a maximum thermal spatial resolution of $\sim 3 \mu \mathrm{m}$ (using a $25 \times$ objective), giving a field-of-view of $464 \mu \mathrm{m} \times 464 \mu \mathrm{m}$ [20]. The IR thermal measurement approach has already been described in [13], [21]. An optical lens was included in the lens turret, enabling switching between IR and visible objectives. 
To make the measurements, the IR thermal source chip was first mounted on an aluminum baseplate, in which a calibrated K-type thermocouple was embedded to monitor the temperature. This assembly was then mounted on a Peltier heater to control the baseplate temperature. The baseplate, with the mounted sample, was positioned underneath the objective of the IR microscope, as shown in Fig. 2. The experimental setup enabled radiation from the sample to be detected both in the IR and optical regions of the spectrum without any realignment of the chip.

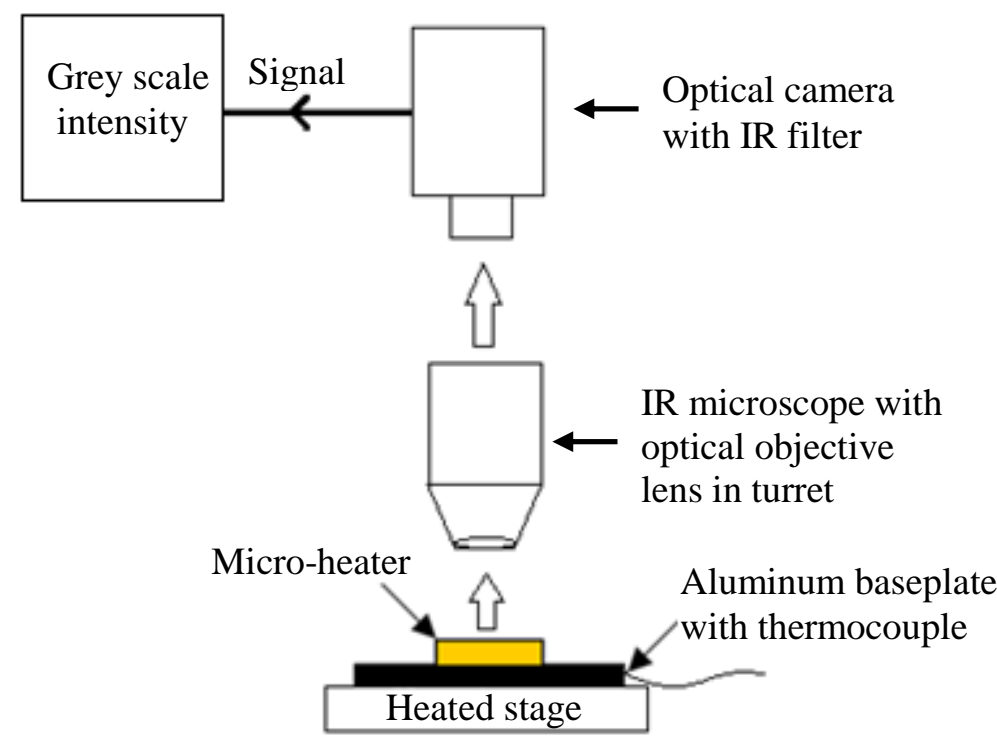

Fig. 2. A schematic diagram showing the experimental set-up used for the thermo-optical measurements

All thermal measurements were made at a baseplate temperature of $80{ }^{\circ} \mathrm{C}\left( \pm 0.5^{\circ} \mathrm{C}\right)$. This temperature was chosen to give an adequate IR detector signal-to-noise ratio. To make electrical contact to the electrodes of the micro-heater, DC probes (Wentworth Laboratories PVX400) were used, which were connected to a DC power supply (TTI PL303QMD-P). The micro-heater was biased using a 4-point probe measurement system [22], with two of the probes used for accurate voltage sensing. DC input powers in excess of $350 \mathrm{~mW}$ were applied to generate heater temperatures greater than the Draper temperature. Fig. 3 shows the incandescent radiation emitted by the microheater above the Draper temperature. The optical camera captured the incandescence image and software (known as ImageJ) was used to compute the intensity of optical incandescent radiation in the form of an 8-bit grey scale value in arbitrary units (a.u.). 


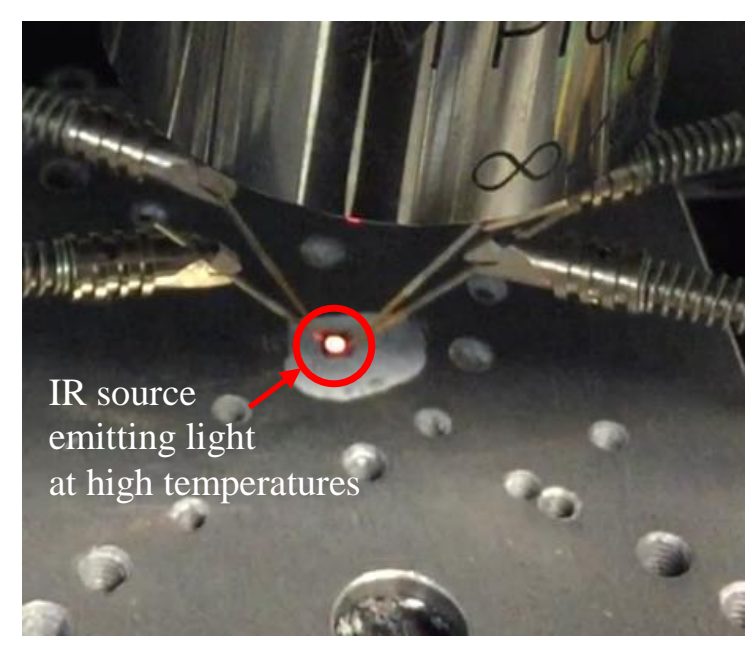

Fig. 3. An optical image of the experimental setup showing the micro-heater of the IR source incandescing at very high operating temperatures $\left(>700^{\circ} \mathrm{C}\right)$.

\subsection{Thermal-incandescence calibration}

To make quantitative thermal-incandescence measurements, the optical radiation emitted from the surface of the micro-heater in the $0.4 \mu \mathrm{m}-0.7 \mu \mathrm{m}$ spectral range was calibrated as a function of temperature using different metal micro-particles with known melting points [Aluminum (Al) $\left(\mathrm{MP}=660.3{ }^{\circ} \mathrm{C}\right)[23]$, silver $(\mathrm{Ag})\left(\mathrm{MP}=961.8^{\circ} \mathrm{C}\right)[24]$, copper $(\mathrm{Cu})\left(\mathrm{MP}=1083.4{ }^{\circ} \mathrm{C}\right)[25]$ and manganese $(\mathrm{Mn})\left(\mathrm{MP}=1245.8^{\circ} \mathrm{C}\right)$ micro-particles] [23]. The micro-particles diameters were in the range of $15 \mu \mathrm{m}-20 \mu \mathrm{m}$, and therefore small enough not to present any significant thermal loading.

The metal micro-particles were placed in isothermal contact with the surface of the microheater (as shown in Fig. 4) using a Scientifica micro-manipulation probe [13]. Naturally occurring electrostatic and Van-der-Waals forces help to adhere the metal micro-particle to the micromanipulation probe, enabling the single micro-particle to be transferred to the measurement point on the surface of the micro-heater. It is also possible to remove the micro-particle from the surface of the device using the manipulator without causing damage to the delicate membrane.

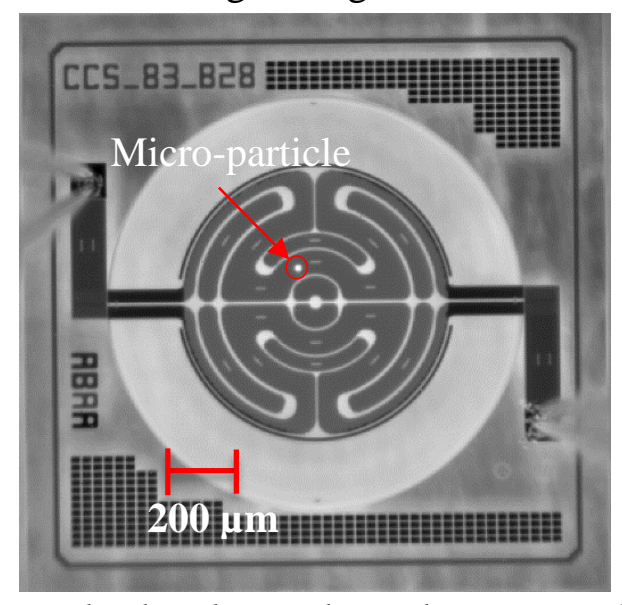

Fig. 4. An image showing the micro-particle placed in isothermal contact on the heater of the IR source chip

The DC bias voltage applied to the micro-heater was slowly increased, thereby increasing the dissipated power and operating temperature, until the melting point of a metal micro-particle was 
recorded by optically detecting the change in phase state from solid to liquid, as shown in Fig. 5. The intensity of optical radiation emitted from the surface of the heater due to incandescence was recorded at the melting point. This was repeated for a range of micro-particles with different melting points to obtain a temperature calibration.

For temperatures above the Draper point the experimental points are found to fit optimally to an exponential curve (which is shown in Fig. 6). The exponential curve follows the intensity of incandescent radiation as a function of temperature, as described by Planck's radiation curve, and discussed in Section 3. The exponential curve provides, to a first order, a calibration of incandescent radiation intensity as a function of temperature and enables the surface temperature to be estimated by measuring the intensity of the emitted optical incandescent radiation.

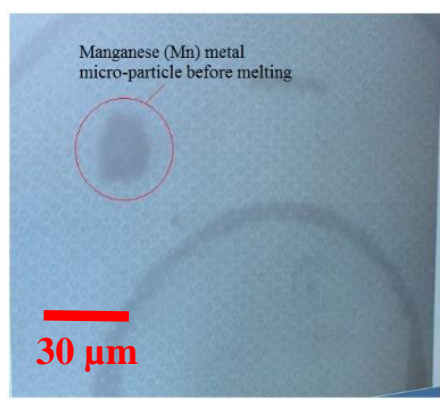

(a)

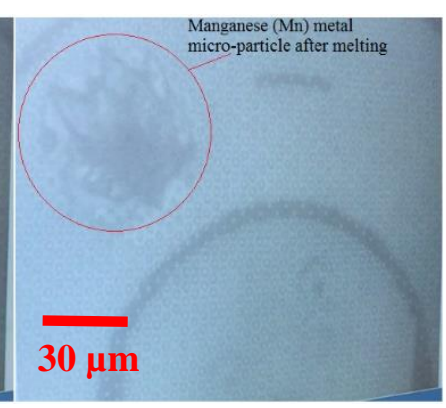

(b)

Fig. 5. An optical image of a Mn metal micro-particle placed on the surface of the micro-heater (a) before melting (b) after melting.

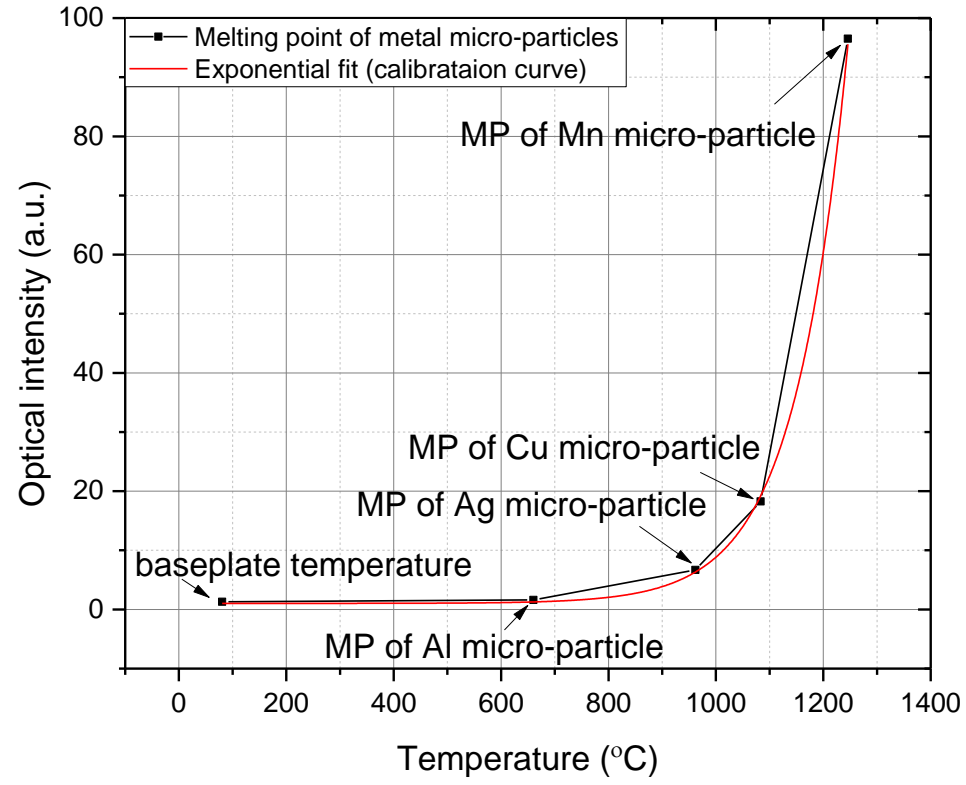

Fig. 6. Calibration curve showing detected incandescent radiation intensity, plotted against the micro-particle melting point temperatures.

For the lower temperature characterization, the thermal measurements on the micro-heater were obtained using the conventional IR microscope. The micro-heater was biased over a range of DC electrical power levels $(0-362 \mathrm{~mW})$ and for each power, a two-dimensional (2D) thermal map of the IR source chip was recorded, using the $25 \times$ lens objective. The peak temperature was identified and plotted as a function of the electrical power (Fig. 7). The maximum temperature rise 
measured by the IR microscope was $774{ }^{\circ} \mathrm{C}$ at an electrical power of $362 \mathrm{~mW}$. Fig. 8 shows a typical 2D thermal image of an electrically biased micro-heater. Temperatures fall away very rapidly from the perimeter of the micro-heater membrane ring structure, indicating limited heating of surrounding regions, and therefore the IR source is thermally safe to use in an integrated electronic circuit.

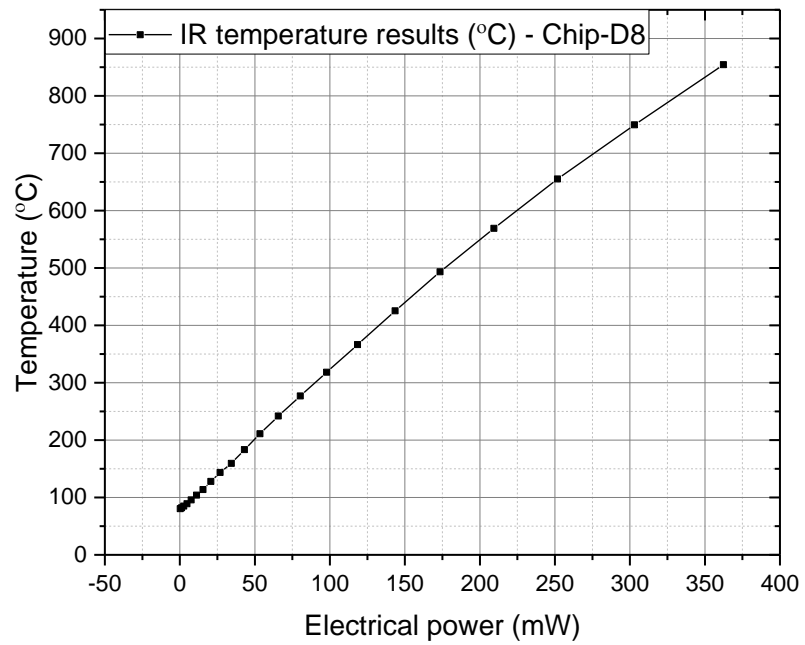

Fig. 7. IR temperature measurement results for the micro-heater as a function of electrical power

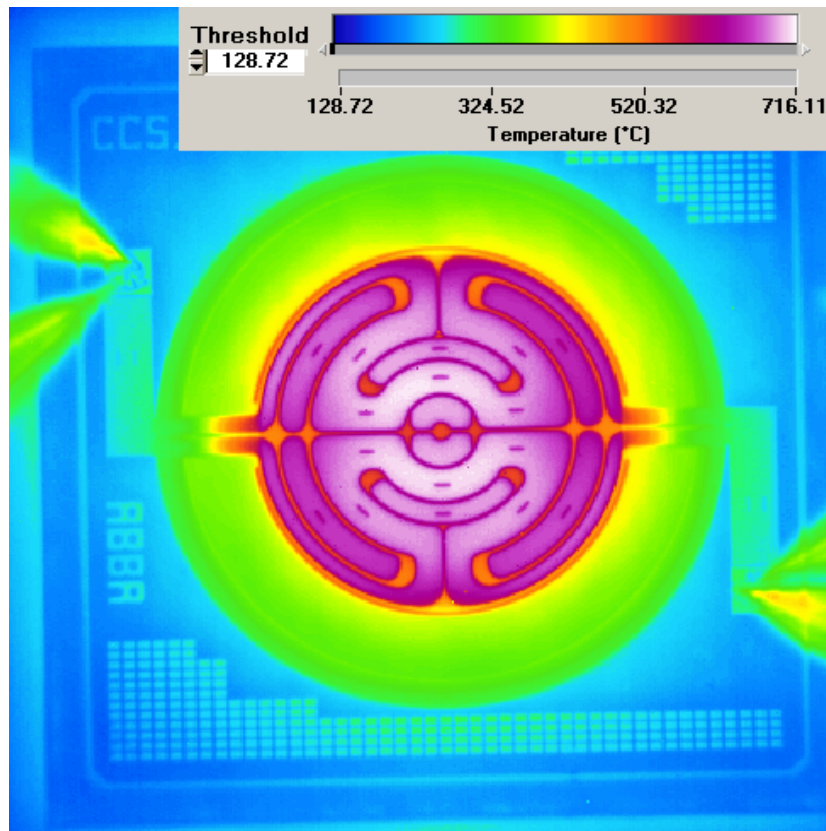

Fig. 8. IR thermal image of the IR source chip (biased at an electrical power of $\sim 275 \mathrm{~mW}$ ), showing the temperature distribution across the micro-heater structure

\section{Results and discussion}

\subsection{Incandescence uniformity results}

Optical incandescence measurements were made on three IR source chip samples biased over a range of DC input powers $\left(0\right.$ to $\sim 760 \mathrm{~mW}$ ) at an ambient of $80^{\circ} \mathrm{C}$. The hottest area on the miniature micro-heater was identified by conventional IR measurement and the optical camera was focused on 
that point. Fig. 9 shows the intensity of optical incandescent radiation measured (a.u.) as a function of DC bias for the three devices, which all showed very similar characteristics, indicating good chipto-chip reproducibility. Therefore, it is reasonable to assume the miniature micro-heater will provide a consistent thermal platform.

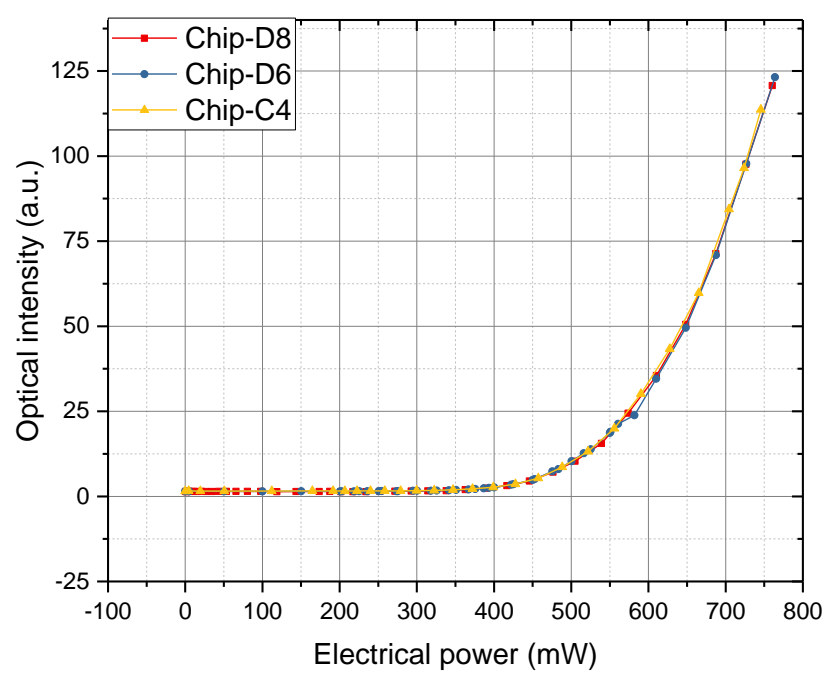

Fig. 9. Optical incandescence radiation intensity measured as a function of micro-heater electrical power.

\subsection{High temperature measurement results}

The thermal-incandescence technique was used to estimate the surface temperature of two IR source chip samples biased at high DC input power levels ( $300 \mathrm{~mW}$ to $\sim 727 \mathrm{~mW}$ ). For each DC electrical power, the optical incandescent radiation intensity was recorded, and the corresponding temperature interpolated using the calibration curve shown in Fig. 6. The method enabled the surface temperature of the IR source chip to be characterized to very high temperatures, approaching 1245 ${ }^{\circ} \mathrm{C}$. The experimental results are shown in Fig. 10.

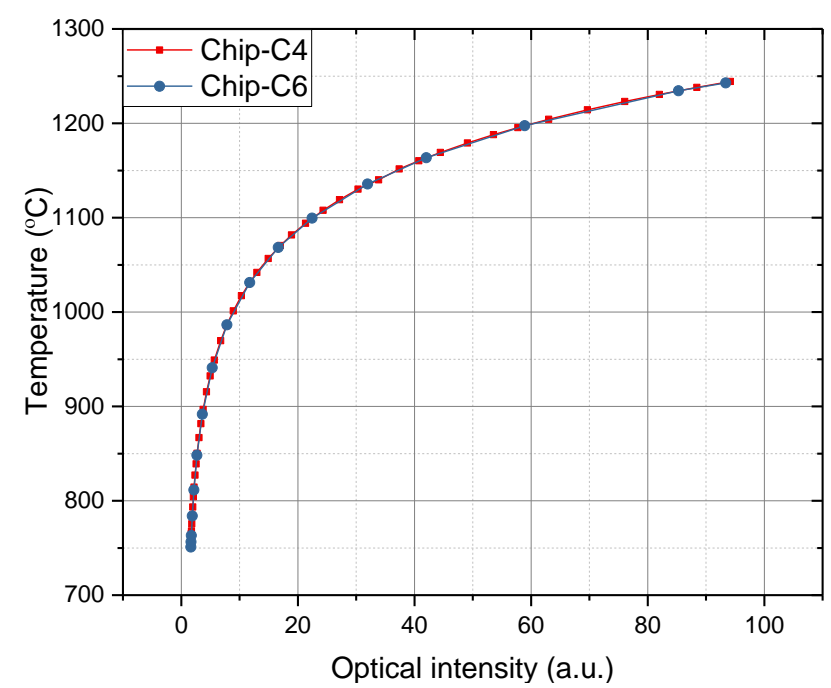

Fig. 10. Temperature measurement results on the micro-heaters obtained from thermal-incandescence measurements, plotted as a function of incandescent radiation intensity 
An electrical method was also utilized to calculate the average temperature of the IR source chip [6], [26]. For this method, the temperature dependent resistance of the micro-heater was measured, taking into account the chip track resistance. Knowing the temperature coefficients of resistance $\left(T C R_{1}=1.88 \times 10^{-3} \mathrm{~K}^{-1}\right.$ and $T C R_{2}=4.6 \times 10^{-7} \mathrm{~K}^{-2}$ provided by ams Sensors UK Ltd. $)$; the average temperature of the IR source chip was calculated [13], using Equation 5.

$$
R=R_{0}\left[1+T C R_{1}\left(T-T_{0}\right)+T C R_{2}\left(T-T_{0}\right)^{2}\right]
$$

where, $T_{0}=$ ambient temperature, $T=$ heater temperature, $R=$ resistance at temperature $T$ and $R_{0}=$ resistance at ambient temperature $T_{0}$.

The heater temperature determined using the electrical method (as a function of electrical power), was compared with temperature measurements obtained by conventional IR measurement for low DC input powers (up to $\sim 300 \mathrm{~mW}$ ) and with the temperatures obtained by the optical incandescence approach for high DC input powers (> $300 \mathrm{~mW})$. The comparison is shown in Fig. 11. A maximum surface temperature of $\sim 1245{ }^{\circ} \mathrm{C}$ was recorded at an input power of $\sim 735 \mathrm{~mW}$. There was reasonable agreement between the temperature results of the optical and electrical methods, as a function of electrical input power to the IR source chip. The electrical method measures the lumped average surface temperature of the IR micro-heaters and as there was good agreement with the IR and optical incandescence spot measurements, which suggests good uniformity of temperature across the surface of the micro-heater.

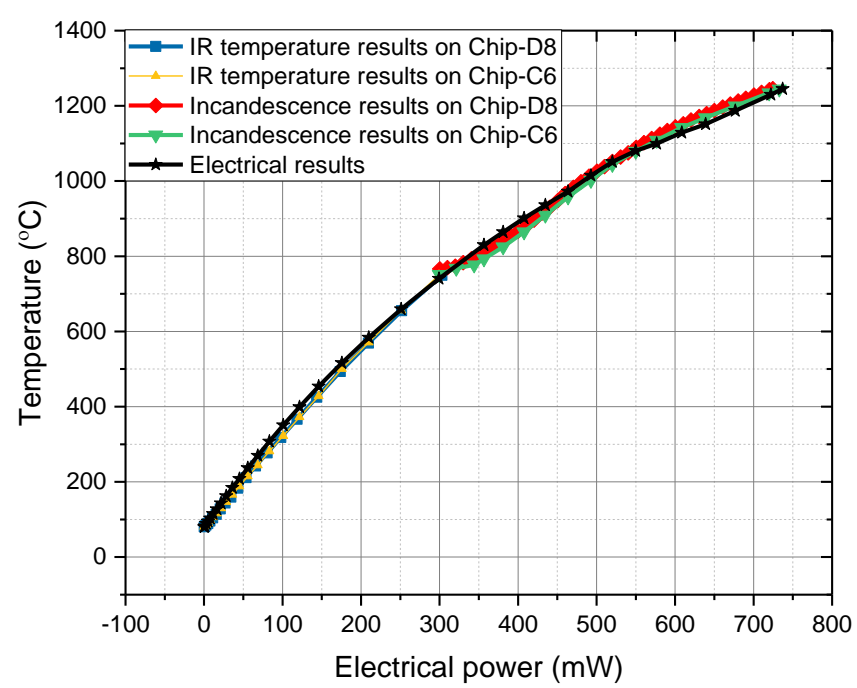

Fig. 11. Comparison between conventional IR, incandescence and electrical temperature measurements of the micro-heaters.

\section{Conclusion}

High temperature thermal characterization of a CMOS based MEMS IR source, fabricated on a $\mathrm{SiO}_{2}$ membrane using tungsten metallization, has been undertaken, for the first time, using thermalincandescence microscopy. Conventional IR imaging was used to thermally characterize the microheater embedded in the IR source chip to temperatures below $\sim 700{ }^{\circ} \mathrm{C}$ and optical incandescence to elevated temperature in excess of $1200{ }^{\circ} \mathrm{C}$. The known melting points of metal micro-particles were used to calibrate the thermal-incandescence approach as a function of temperature.

The temperature results obtained from the thermo-optical measurements, were compared to 
those obtained using an electrical method. There was reasonable (max error $\pm 3.5 \%$ ) agreement between the optical and electrical temperature measurements, suggesting good temperature uniformity across the micro-heater of the IR source. The measurement technique shows potential for increasing the temperature range of an IR microscope by integrating an optical camera for high temperature characterization of electronic devices.

\section{Acknowledgements}

The authors would like to thank ams Sensors Limited, Cambridge, UK, for the supply of the CMOS based MEMS IR thermal source.

\section{References}

[1] D. Pierścińska, Thermoreflectance spectroscopy-Analysis of thermal processes in semiconductor lasers, Journal of Physics D: Applied Physics. 51 (2018) 013001. https://doi.org/10.1088/1361-6463/aa9812.

[2] J. Christofferson, K. Maize, Y. Ezzahri, J. Shabani, X. Wang, A. Shakouri, Microscale and Nanoscale Thermal Characterization Techniques, J. Electron. Packag. 130 (2008) 041101041101-6. https://doi.org/10.1115/1.2993145.

[3] C.H. Oxley, R.H. Hopper, G. Hill, G.A. Evans, Improved infrared (IR) microscope measurements and theory for the micro-electronics industry, Solid-State Electronics. 54 (2010) 63-66. https://doi.org/10.1016/j.sse.2009.09.022.

[4] R. Hopper, S. Ali, M. Chowdhury, S. Boual, A. De Luca, J.W. Gardner, F. Udrea, A CMOSMEMS Thermopile with an Integrated Temperature Sensing Diode for Mid-IR Thermometry, Procedia Engineering. 87 (2014) 1127-1130. https://doi.org/10.1016/j.proeng.2014.11.363.

[5] S.Z. Ali, A.D. Luca, R. Hopper, S. Boual, J. Gardner, F. Udrea, A Low-Power, Low-Cost Infra-Red Emitter in CMOS Technology, IEEE Sensors Journal. 15 (2015) 6775-6782. https://doi.org/10.1109/JSEN.2015.2464693.

[6] D. Bauer, M. Heeger, M. Gebhard, W. Benecke, Design and fabrication of a thermal infrared emitter, Sensors and Actuators A: Physical. 55 (1996) 57-63. https://doi.org/10.1016/S09244247(96)01250-2.

[7] M. Weber, P. Lerch, P. Renaud, Improved design for fast modulating IR sources, J. Micromech. Microeng. 7 (1997) 210. https://doi.org/10.1088/0960-1317/7/3/034.

[8] S.Z. Ali, A. De Luca, Z. Racz, P. Tremlett, T. Wotherspoon, J.W. Gardner, F. Udrea, Low power NDIR CO2 sensor based on CMOS IR emitter for boiler applications, in: IEEE SENSORS 2014 Proceedings, IEEE, Valencia, Spain, 2014: pp. 934-937. https://doi.org/10.1109/ICSENS.2014.6985155.

[9] S.Z. Ali, F. Udrea, W.I. Milne, J.W. Gardner, Tungsten-Based SOI Microhotplates for Smart Gas Sensors, Journal of Microelectromechanical Systems. 17 (2008) 1408-1417. https://doi.org/10.1109/JMEMS.2008.2007228.

[10] I.E. Gordon, L.S. Rothman, C. Hill, R.V. Kochanov, Y. Tan, P.F. Bernath, M. Birk, V. Boudon, A. Campargue, K.V. Chance, B.J. Drouin, J.-M. Flaud, R.R. Gamache, J.T. Hodges, D. Jacquemart, V.I. Perevalov, A. Perrin, K.P. Shine, M.-A.H. Smith, J. Tennyson, G.C. Toon, H. Tran, V.G. Tyuterev, A. Barbe, A.G. Császár, V.M. Devi, T. Furtenbacher, J.J. Harrison, J.-M. Hartmann, A. Jolly, T.J. Johnson, T. Karman, I. Kleiner, A.A. Kyuberis, J. Loos, O.M. Lyulin, S.T. Massie, S.N. Mikhailenko, N. Moazzen-Ahmadi, H.S.P. Müller, O.V. Naumenko, A.V. Nikitin, O.L. Polyansky, M. Rey, M. Rotger, S.W. Sharpe, K. Sung, E. Starikova, S.A. Tashkun, J.V. Auwera, G. Wagner, J. Wilzewski, P. Wcisło, S. Yu, E.J. Zak, 
The HITRAN2016 molecular spectroscopic database, Journal of Quantitative Spectroscopy and Radiative Transfer. 203 (2017) 3-69. https://doi.org/10.1016/j.jqsrt.2017.06.038.

[11] M. Yu, Y. Okawachi, A.G. Griffith, N. Picqué, M. Lipson, A.L. Gaeta, Silicon-chip-based mid-infrared dual-comb spectroscopy, Nature Communications. 9 (2018) 1869. https://doi.org/10.1038/s41467-018-04350-1.

[12] J.R. Mahan, Radiation Heat Transfer: A Statistical Approach, John Wiley \& Sons, 2002.

[13] P. Pandey, C. Oxley, R. Hopper, Z. Ali, A. Duffy, Infra-red thermal measurement on a lowpower infra-red emitter in CMOS technology, IET Science, Measurement \&amp; Technology. (2018). https://doi.org/10.1049/iet-smt.2018.5427.

[14] A.D. Luca, S.Z. Ali, F. Udrea, On the reproducibility of CMOS plasmonic mid-IR thermal emitters, in: 2017 International Semiconductor Conference (CAS), 2017: pp. 101-104. https://doi.org/10.1109/SMICND.2017.8101168.

[15] M.E. Castagna, R. Modica, S. Cascino, M. Moschetti, V. Cerantonio, A. Messina, A. Santangelo, A high stability and uniformity W micro hot plate, Sensors and Actuators A: Physical. 279 (2018) 617-623. https://doi.org/10.1016/j.sna.2018.06.046.

[16] M. Rydberg, U. Smith, Long-term stability and electrical properties of compensation doped poly-Si IC-resistors, IEEE Transactions on Electron Devices. 47 (2000) 417-426. https://doi.org/10.1109/16.822289.

[17] A. Pusch, A. De Luca, S.S. Oh, S. Wuestner, T. Roschuk, Y. Chen, S. Boual, Z. Ali, C.C. Phillips, M. Hong, S.A. Maier, F. Udrea, R.H. Hopper, O. Hess, A highly efficient CMOS nanoplasmonic crystal enhanced slow-wave thermal emitter improves infrared gas-sensing devices, Sci Rep. 5 (2015). https://doi.org/10.1038/srep17451.

[18] R. Siegel, H. John, Thermal Radiation Heat Transfer, Fourth Edition, CRC Press, 2001.

[19] E. Brodu, M. Balat-Pichelin, J.-L. Sans, J.C. Kasper, Evolution of the emissivity of tungsten at high temperature with and without proton bombardment, Acta Materialia. 84 (2015) 305316. https://doi.org/10.1016/j.actamat.2014.10.050.

[20] C.H. Oxley, R.H. Hopper, G.A. Evans, Improved infrared (IR) microscope measurements for the micro-electronics industry, in: 2008 2nd Electronics System-Integration Technology Conference, 2008: pp. 215-218. https://doi.org/10.1109/ESTC.2008.4684352.

[21] R. Hopper, C. Oxley, Thermal measurement a requirement for monolithic microwave integrated circuit design, Proc. ARMMS. (2008) 385-390.

[22] J. Glover, The design and thermal measurement of III-V integrated micro-coolers for thermal management of microwave devices, Ph.D., De Montfort University, 2016. http://hdl.handle.net/2086/13299 (accessed June 8, 2019).

[23] Metals - Melting Temperatures, (n.d.). https://www.engineeringtoolbox.com/meltingtemperature-metals-d_860.html (accessed December 11, 2018).

[24] Silver - Melting Point - Boiling Point, Nuclear Power. (2018). https://www.nuclearpower.net/silver-melting-point-boiling-point/ (accessed December 11, 2018).

[25] Copper GF52483664, Sigma-Aldrich. (n.d.). https://www.sigmaaldrich.com/catalog/product/aldrich/gf52483664 (accessed December 11, 2018).

[26] S.Z. Ali, Electro-thermo-mechanical study of membrane devices for smart IC technologies, Ph.D., University of Cambridge, 2008.

http://ethos.bl.uk/OrderDetails.do?did=1\&uin=uk.bl.ethos.595441 (accessed January 31, 2017). 